\title{
The mechanism of influence of neurotechnologies on the formation of the sixth technological order in the economy and society
}

\author{
Glushchenko Valery Vladimirovich ${ }^{1}$, Kulkov Daniil Andreevich², Alenin llya Aleksandrovich ${ }^{3}$ \\ ${ }^{1}$ Associate Professor Center for Project Activities Moscow Polytechnic University, \\ Moscow, Russia \\ ${ }^{2,3}$ Department,Senior Lecturer, Department of Foreign Languages Moscow Polytechnic University, Moscow, Russia
}

\begin{abstract}
: the subject of this work is the study of the mechanism of the effect of "neurotech" technologies on the formation of the sixth technological order in engineering; the object of the article is dedicated to the sixth technological order in engineering, the aim is to increase the efficiency of the processes of development of the sixth technological order in mechanical engineering based on the development of the theoretical foundations of neurotechnology in mechanical engineering. For achieving this goal, the following tasks are solved: the study of the concept, content, structural elements of the sixth technological order in post-industrial engineering; the description of the essence and content of neurotechnologies in post-industrial engineering; the development of methods of logical analysis and synthesis of neurotechnologies in post-industrial engineering; the formation of a criteria base for evaluating the effectiveness of the processes of the development of neurotechnological engineering within the sixth technological order. The research methods in the article are synthesis and analysis, logical and historical analysis, heuristic synthesis, system and comparative analysis, search and normative forecasting, expert assessments, the scientific novelty of the article is connected with the study of the appearance of the sixth technological order in mechanical engineering, the mechanism of influence of neurotechnologies on the development of the sixth technological order in post-industrial engineering.
\end{abstract}

Keywords: sixth technological order, neurotechnology, engineering, mechanism, methodology.

\section{INTRODUCTION}

The relevance of the article in 2021 is determined by the creation of a roadmap for the development of neurotechnologies within the framework of the national technological initiative in the interests of forming the sixth technological order and increasing the competitiveness of domestic engineering due to the accelerated development of the neuroengineering segment and increasing its influence on global markets.

The hypothesis of this article is the statement that in order to accelerate the development of the neuroengineering segment and the sixth technological paradigm, to ensure the growth of the practical efficiency of work and business initiatives in this area, it is necessary to study and form a mechanism to increase the practical efficiency of the effect of neurotechnologies in order to create the sixth technological paradigm in postindustrial mechanical engineering.

The purpose of the article is to increase the efficiency of the development processes of the sixth technological order in mechanical engineering based on the development of theoretical foundations and the mechanism of influence of neurotechnologies in post-industrial engineering. To achieve this goal, the following tasks are solved: to research the concept, content and structural elements of the sixth technological order in post-industrial mechanical engineering.

- to describe the essence and content of neurotechnologies in postindustrial mechanical engineering and to describe the development of methods for logical analysis and synthesis of neurotechnologies in postindustrial mechanical engineering,

- to form a criterion base for assessing the effectiveness of the development processes of neuroengineering within the framework of the sixth technological order.

The object of the article is the sixth technological order in mechanical engineering.

The subject of the work is the study of mechanisms of influence of neurotechnologies in order to increase the efficiency of the formation of the sixth technological order in postindustrial mechanical engineering.

The mechanism of influence of neurotechnologies will be called a set of methods and tools for the influence of neurotechnologies on the process of the formation of the sixth technological order in the economy and society.

A transition to the sixth technological order is happening at the beginning of the 21 st century $[1,2]$. By the 
term 'the technological order 'we mean a systematic unity of technologies (the technological basis of socio-economic development) that are at a similar technical level and their development is interconnected and synchronized. It is predicted that the basis of the sixth technological order will be nanotechnology, biotechnology, nanoenergy, molecular, cellular and nuclear technologies, nanobiotechnology, biomimetics and all kinds of nanoscale production.

Based on this order new areas of science and technology will be developed such as: new medicine (living tissues and organs, reconstructive surgery and medicine), household appliances, models of transport and communications; stem cell application, genetic engineering. It is believed that the main element of products within the sixth technological order will be microelectronics and components of microelectronics. The key achievement of this paradigm may be the individualization of objects and processes of production and consumption, an intensive reduction in the material and energy consumption of industrial production processes, the creation of materials and goods with projected properties and characteristics. According to well-known forecasts, the humanitarian consequence of the development of the sixth technological order may be a significant improvement in the quality of life and, on this basis, an increase in the life expectancy of humans and animals. According to expert estimates, in 2010 in the most developed countries technologies attributed to the fifth technological order were about $60 \%$, technologies of the fourth order were about $20 \%$, and the share of technologies of the sixth technological order was close to $5 \%$. It is predicted that developed countries may enter the sixth technological order already at the end of the second decade of the 21 st century.

In this regard, research is being actively carried out: the conditions for the formation and leading sectors of the sixth technological order; prospects for the formation of this structure [3]; the possibility of using neurotechnologies in transport is being studied [4]. The analysis of the results of research on the development of the sixth technological order presented in this article shows that neurotechnologies and the process of their development are not considered as a structural element of the sixth technological order and are not yet included in its structure. It is hereby proposed to include the development of neurotechnologies in the structure of the sixth technological order, as one of its main elements and components. The basis for such a proposal may be that neuroeconomics and neuromarketing are already considered as tools for managing the development of organizations [5]. A great future is recognized for neurotechnologies [6], in particular, the possibility of reducing the workload on employees is recognized [7], which will lead to an improvement in the quality of working life and life in general.
At the same time, neurotechnologies are suitable for analyzing complex situations in the development of large systems [8] and therefore can influence the development and formation of the sixth technological order in the economy and, in particular, in mechanical engineering. In particular, the use of technology in making managerial decisions in conditions of uncertainty [9] can contribute to solving one of the key tasks of the sixth technological order, namely, the task of increasing the efficiency of social production. Attention is drawn to the fact that neurotechnology (along with and simultaneously with nanotechnology) can increase the efficiency and safety of the use of natural resources [10]. Researchers note that neurotechnology can play a large role in the new industrial development [11].

At the same time, the very development of neurotechnologies can contribute to the modification of social feedback [12], influence the socio-cultural space [13], and thus make the necessary changes in the work of development institutions in the formation of the sixth technological order [1,2]. In addition, neurotechnologies can influence the development of the sixth technological order due to their great role in the development of the digital economy [14]. At the same time, neurotechnologies can be considered as an object of activity and development of new industrial sectors [15] and branches of the digital economy [16], in particular, it is expected to introduce neurotechnologies in education [17], which is considered as an important tool for the formation of the sixth technological order. Thus, studying the materials of this article we can draw a conclusion. There are various and fairly strong reasons for the inclusion of neurotechnologies in the system-forming parts of the sixth technological order. At the same time, it should be noted that the development of neurotechnologies is not only promising, but also involves significant risks [18].

As one of the qualitative and / or quantitative indicators of the development of neurotechnologies in our country we should consider the place of the Russian economy in the market for this kind of technology [19], for example, the percentage of the market or the place of Russia in the ranking of the most developed countries in this direction. At the same time, the analysis of the prospects for the development of neurotechnologies [20] is of great importance not only for the purpose development, but also for the development of the sixth technological order.

A proper roadmap can play an important role in the development of neurotechnologies in our country. In particular, roadmap provides a definition, which notes that neurotechnologies are technologies that are based on understanding of the work of the human brain, higher nervous activity, including technologies that enhance, improve the functioning of the human brain and / or human mental activity [21]. 


\section{Method}

At the same time, studies of neuromarketing (which acts as a structural element of neurotechnology) show that a broader representation of this area of neurotechnology is possible $[22,23]$.

In this article, it is proposed to understand neurotechnology as a systemic combination of initial resources, methods and tools of activity, qualification skills of personnel that allow synthesizing and providing products that increase the efficiency and / or safety of human activity in socio-economic systems. At the same time, a specific feature of the methods and tools involved in the creation and application of neurotechnologies is the use of knowledge about higher nervous activity, physical measurements of a person's reactions to external factors.

The results of these works [22,23] allow us to recognize the field of application of neurotechnologies:

1) Study of higher nervous activity and / or biological reactions of a person to external stimuli in the interests of better understanding and / or assistance in understanding the work of the brain, higher nervous activity, in the interests of creating devices and systems aimed at increasing the efficiency and sustainability of socio-economic development;

2) The study of paradoxical human behavior in the processes of socio-economic development (neuroeconomics and neurosociology) in the interests of using the knowledge gained when creating systems that limit the damage from such behavior and, more broadly, in the interests of the sustainability and safety of socio-economic development;

3) The formation of training programs and systems based on a game-based approach of learning, in the interests of improving the quality of education, etc.

In this article the term neurosociology means a part of sociology, the object of which is the illogical, such as paradoxical behavior of people in social and industrial relations, in particular, in situations of stress. At the same time, the development of scientific support of neurotechnologies is recommended and should be carried out and studied within the framework of the general scientific support of innovative activity [24].

The mechanism of the influence of neurotechnologies on the development of the sixth technological order in postindustrial mechanical engineering in this article will be called a set of methods, methods and tools used in the process of such development. In this article, using the term postindustrial neuroengineering it is proposed to mean the sector of high-tech mechanical engineering, the philosophy and culture of functioning of which is focused on the synthesis of new needs based on the results of scientific and technological progress and the satisfaction of these new and / or previously hidden (latent) needs of the economy and / or society in mechanical engineering products based on the development and practical application of neurotechnologies.

When studying the impact of neurotechnologies on the formation of the sixth technological order in postindustrial mechanical engineering, it is recommended to take into account that for a long time the risks of innovation activity remain high: according to F. Kotler, the risks depending on the type of market are in the range of $18-40 \%$ [25, p.288 ]; the average share of unsuccessful innovative projects over the previous decades (in Japan and Great Britain) ranged from $40 \%$ to $60 \%[26,27,28]$.

The development of neurotechnologies within the framework of the sixth technological order occurs against the background of the formation of a post-industrial approach to marketing [29]. Post-industrial marketing focuses on the formation of new needs among buyers and their satisfaction through the implementation of the achievements of scientific and technological progress. The next feature of neurotechnologies in the sixth technological order is the formation of technological and scientific platforms [30]. At the same time, the methodology for forming a strategy for the transition to the sixth technological order is described in article [1]. To assess the possibility of introducing neurotechnologies (and other technologies of the sixth technological order (STO) in the organization's products, a special table can be developed. Such a table can be called the table of implementation (multiplication) of STO technologies in the company's products. Such tables can be developed at a specific enterprise for each type of products manufactured in order to determine the possibility (and, subsequently, economic feasibility) of applying the technologies of the new technological order in the products of the previous technological order.

Rows of this kind of table can correspond to subsystems (elements) of products of the previous technological order. The columns of this table should correspond to the technologies of the new technological order. At the intersection of a row and a column, "+1" is put down if the element corresponding to the row number can be modified by combining (aggregated) with the technology of the new technological paradigm.

Example: Let us consider the possibility of multiplying the technologies of the sixth technological order (STO) with the elements of products of the 4th technological order (internal combustion engine), for example, a car.

The rows in this table will correspond to the vehicle subsystems (engine, chassis, interior, trunk). The columns of this table will correspond to the STO technologies (nanotechnology, digitalization, information, intelligent, environmental). Consider the multiplication of PCS technologies with a car engine. Nanotechnology can increase the strength and wear resistance of engine parts, thereby increasing its resource (assigned service life, MTBF) - therefore we put " +1 " at the intersection of a row 
and a column. Digitalization technologies will help to measure the speed of rotation of the motor shaft (put "+1"). Information technologies will help transmit information about the shaft rotation speed through the GLONASS system (we put "+1") and so on. The analysis of the technological order can be qualitative and quantitative; complex and thematic and more.

Below is a table (Table 1) analysis of the possibility of introducing STO technologies into a car (products of the fourth technological order) and its subsystem during the transition of an enterprise to STO (see Appendix No. 1).

We can assume (propose a hypothesis) that for machine-building corporations, the driving motive for introducing neurotechnologies into the processes of their functioning, research, development and R\&D management can be:

- Creation of new markets for mechanical engineering products within the framework of the sixth technological order.

- The desire to reduce the risks of innovative projects and thereby increase the financial results of their activities.

The tasks of using neurotechnologies in the process of forming the sixth technological order in mechanical engineering are:

- Increasing the efficiency of machine-building corporations at all stages of the life cycle of machine-building products, forming more effective competitive strategies in the markets;

- An increase in the accuracy of information on the issues of knowledge of the motives and processes of decision-making made by buyers purchasing neuroengineering goods (improving trade neuromarketing);

- An increase in the likelihood of making more effective innovative technical and technological solutions in the course of developing new models of mechanical engineering products (scientific research neurotechnologies), and more.

The general theory of the formation and development of neurotechnologies (neurotechnology) can become the methodological basis for the formation of the mechanism of the influence of neurotechnologies on the development of the sixth technological order in mechanical engineering and the basis for the formation of neuroengineering as a new direction in mechanical engineering of the sixth technological order.

The complete theory of neurotechnologies, as a structural element of scientific support for the development of neurotechnologies, the formation of a segment of neuroengineering within the sixth technological order, should reflect the essence of neurotechnologies, implement functions and roles that can be described by analogy with the methodological provisions of [24].

TABLE I. ANALYSIS OF THE POSSIBILITY OF IMPLEMENTING STO TECHNOLOGIES IN THE CAR AND ITS SUBSYSTEMS DURING THE TRANSITION OF THE ENTERPRISE TO THE SIXTH TECHNOLOGICAL ORDER (FRAGMENT).

\begin{tabular}{|c|c|c|c|}
\hline № & $\begin{array}{l}\text { Technologi } \\
\text { es / } \\
\text { Subsystems }\end{array}$ & $\begin{array}{c}\text { Nanotech } \\
\text { Technologies }\end{array}$ & Neurotechnologies \\
\hline 1. & $\begin{array}{c}\text { The car as a } \\
\text { whole } \\
\text { (system) }\end{array}$ & $\begin{array}{l}\text { Increasing the strength } \\
\text { and wear resistance of } \\
\text { parts, } \\
\text { increasing the } \\
\text { durability of paints, etc. }\end{array}$ & $\begin{array}{l}\text { Analysis of the state } \\
\text { of the driver, " } \\
\text { gamification of } \\
\text { driving training» }\end{array}$ \\
\hline $\begin{array}{c}1 . \\
1 \\
\end{array}$ & Car engine & $\begin{array}{l}\text { Increasing the strength } \\
\text { and wear resistance of } \\
\text { parts }\end{array}$ & $\begin{array}{l}\text { Protecting the engine } \\
\text { from illogical driver } \\
\text { behavior }\end{array}$ \\
\hline $\begin{array}{l}1 . \\
2\end{array}$ & Car body & $\begin{array}{l}\text { Improving the strength } \\
\text { and wear resistance of } \\
\text { body parts, improving } \\
\text { the quality of paint }\end{array}$ & $\begin{array}{l}\text { Registration of } \\
\text { customer reactions } \\
\text { to changes in car } \\
\text { design }\end{array}$ \\
\hline $\begin{array}{l}1 . \\
3 .\end{array}$ & $\begin{array}{l}\text { Undercarria } \\
\text { ge }\end{array}$ & $\begin{array}{l}\text { Improving the strength } \\
\text { and wear resistance of } \\
\text { body parts, improving } \\
\text { the quality of paint }\end{array}$ & $\begin{array}{l}\text { Registration of } \\
\text { drivers ' reactions to } \\
\text { changes in the } \\
\text { behavior of the car } \\
\text { on the road }\end{array}$ \\
\hline $\begin{array}{l}1 . \\
4 .\end{array}$ & Car interior & $\begin{array}{l}\text { Improving the strength } \\
\text { and wear resistance of } \\
\text { interior trim materials }\end{array}$ & $\begin{array}{l}\text { Determination and } \\
\text { maintenance of the } \\
\text { optimal temperature } \\
\text { regime }\end{array}$ \\
\hline $\begin{array}{l}1 . \\
5 .\end{array}$ & $\begin{array}{c}\text { Car display } \\
\text { panel }\end{array}$ & $\begin{array}{l}\text { Improved color display } \\
\text { of vehicle performance } \\
\text { indicators }\end{array}$ & $\begin{array}{l}\text { Analysis of the } \\
\text { convenience of the } \\
\text { location of the } \\
\text { displayed indicators }\end{array}$ \\
\hline
\end{tabular}

The cognitive (epistemological) value of the general theory of neurotechnology will be determined by the ability of this theory to accentuate, systematize and accelerate scientific research in the field of theoretical foundations of neurotechnology and neuro-machine building products. The theoretical tasks of the general theory of neurotechnologies may consist in the development of those described in [24] functions (methodical, cognitive, instrumental, system-forming, law-making, etc.) of the theory of neurotechnology.

The practical role of the formation and further development of the complete theory of neurotechnologies as a tool for the formation of the sixth technological order in mechanical engineering can be as follows:

1) Creation of a new promising market for neurotechnological engineering products (creation of neuroengineering);

2) An increase in the financial results of the economic activities of machine-building corporations through the use of managerial neurotechnologies;

3) Development and clarification of the description of the object of activity, the formation of 
boundaries, the expansion of the field of practical research and production activities of organizations working in this area, including those within the framework of neuroengineering platforms and others.

Based on the generalization and structuring of the study results in the object and subject of neurotechnologies, such additional theoretical and practical tasks of the general theory of neurotechnologies and their application in neuroengineering can be determined:

- Finding the most promising aspects of neurotechnological practice and science, design technologies and production of neuromachinebuilding products (goods and services);

- Determination of the legal framework and / or restrictions on the use of neurotechnologies, taking into account the rights of individuals and legal entities, trade secrets, and other socioeconomic and moral factors;

- Formation of a scientific and methodological base for the development of scientific and technological platforms in the field of innovations related to the spheres of neurotechnology and neuromachinery;

- Scientific substantiation and practical creation of a market scientific and innovative infrastructure for organizational and financial support for the development of neuroengineering;

- Integration of efforts of science, practice and education for solving scientific and practical problems of the development of a neurotechnological platform in post-industrial mechanical engineering of the sixth technological order.

Due to the fact that the definition of the concept of "neurotechnology" has not yet been established, it is important to clarify this concept from a meaningful point of view in this work. It is proposed that neurotechnologies, in their broad sense, be understood as part of the methods of scientific research and practice aimed at synthesis, selection, use of optimal (in a certain criterion sense) methods and tools for the implementation of practical tasks in any areas of activity (research, innovation, management, trade in the organization) created on the basis of the use of knowledge about the higher nervous activity of a person, biological reactions and behavioral acts of employees, customers, competitors of the organization.

The mission of the creation and development of neurotechnologies and neuroengineering can be considered as an increase in the efficiency of the corresponding types of work (activities) in organizations clients of engineering corporations and / or the development of new goods and services (products) in the neuroengineering of the sixth technological order, taking into account the requirement of compliance with the norms of positive and / or natural law in relation to a person. At the same time, the requirement to minimize the possibility of unfair use of neurotechnologies by actors should be taken into account, for example, in the interests of manipulating the subjects of socio-economic relations (consumers, intermediaries, personnel).

The following areas can be called the structural elements of neurotechnology development: trade neuromarketing; management neuromarketing, scientific research of neurotechnologies and others.

The vision of the development of neuroengineering within the framework of the sixth technological order can be called the inspiring subjects (actors) of this process (investors, scientists, managers, etc.) scenario for the development of neurotechnologies as an object and subject of activity in neuroengineering . For example, investors will be attracted by the rapid growth in the cost of capital and a place of honor in the hierarchy of entrepreneurial activity. Scientists will be motivated by the possibility of new scientific discoveries in the process of research, innovation, the possibility of securing copyright to them, the possibility of receiving prestigious scientific awards and rewards for scientific and / or inventive work done. Managers should be motivated by the anticipated rapid growth of the neuromachinery segment and the enticing career prospects arising at the same time (with a corresponding increase in administrative power, material remuneration and social status), and more.

The content and essence of managerial and trade neuromarketing were investigated in works $[22,23]$.

Following problems can be solved by the research of neurotechnologies in mechanical engineering:

- Analytical plan, to research stages of development, subjective perception of objective indicators of processes, etc.;

- Creative, product-production nature, including the synthesis of neurotechnological technical means (goods) and services, including the use of neurotechnologies to optimize the appearance of these goods and / or their individual characteristics;

- Sales maximization, which can cover the creation of a new need for customers using neurotechnologies, as well as the development and monitoring of strategies and tactics for product promotion and other;

- A formative task, which consists in motivating and stimulating the active use of research neurotechnologies in the activities of neuroengineering firms (corporations);

- Managerial task of neurotechnologies, which consists in increasing the efficiency of resources 
used in the activities of neuroengineering corporations through the use of neurotechnologies within all functions of innovation management (planning, organization, motivation and control) in innovative projects.

Following roles of scientific research of neurotechnologies in machine-building corporations of the sixth technological order can be considered:

- The formation of a new segment of the market for goods and services in mechanical engineering of the sixth technological order (neuromachinery) and the implementation of prospects for increasing the production of neuroengineering devices, products, automated workstations to cover the existing and latent potential demand for these goods and services.

- An increase in the competitiveness of organizations and an increase in the financial results of research, production, trading activities of neuromachinery corporations.

- Reducing the likelihood of negative consequences of risks and / or reducing damage from errors and / or ineffective management of research, production, trading activities in machine-building corporations within the framework of the sixth technological order.

By the philosophy of research neurotechnologies in the work of a machine-building company in the sixth technological order, we mean the most general, wise view of: the need for and the possibility of application in scientific, innovative activity, development work in machine-building firms; the use of neurotechnologies in the interests of increasing the economic efficiency of work and / or reducing risks in the work of a neuroengineering (or other) corporation. The philosophy of using neurotechnologies in the work of neuromachinery and other firms of the sixth technological order is part of the philosophy of the sixth technological order and, at the same time, the philosophy of the activity of a neuromachine-building company.

The philosophy of research (managerial, production, trade) neurotechnologies gets its practical expression in the principles of 1 activities in companies in the sixth technological order. Such principles of corporations, organizations, firms reflect the basic values, rules, techniques of neurotechnological activity that form the organizational culture of this activity.

The principles of synthesis and use of research neurotechnologies can be described by analogy with the well-known principles of such research activities as marketing [29]:
- The principle of orientation (far sight) to the future in research of neurotechnologies in neuromachinery companies is reflected in the advanced development of methodology, strategy and research tactics, methods of designing neurotechnological complexes of technical means and equipment.

- The principle of focusing on solving problems (meeting needs) in research (managerial, trade) neurotechnologies directs manufacturers of neurotechnological equipment to form new needs in such equipment and technologies among potential buyers using a client-oriented approach based on the study of their business and technological processes.

- The principle of the complexity of neurotechnological activity (approach) consists in the systemic integration of philosophy, methodology, design tools for a complex of technical means of research (managerial, trade) neurotechnologies for the entire innovative project or production process in postindustrial neuromachinery;

- The principle of concentration of neurotechnological methods and / or technologies is that the concentration of neuromarketing technologies should ensure the emergence of a positive significant impact on the work of neuroengineering corporations and organizations their clients.

- The principle of adaptability and flexibility in neurotechnological activity is associated with the need to adapt the system of neurotechnological research (production, management, trade) to changes in external conditions and / or the state of the external environment of a neuroengineering corporation and / or its clients.

- The principle of coordinating the impact on the consumer (client) with adaptation to changes in the external and internal environment of activity requires ensuring the effective impact of neurotechnology on those who make management decisions in companies related to the usage of neurotechnological products.

Herewith, the economic efficiency of applying the neurotechnological methods of the economic and financial activity in an organization which applies such technologies in its work can be identified using mathematical dependencies.

The increase of profit after implementing neuromarketing technologies and devices in enterprises can be calculated by using the following formula:

$$
\mathrm{P}_{\mathrm{nti}}=\mathrm{A} * \mathrm{ROA} * \mathrm{~K}_{\mathrm{ri}} * \mathrm{~K}_{\mathrm{pi}} * \mathrm{~K}_{\mathrm{ti}} * \mathrm{~K}_{\mathrm{mi}} \text {; }
$$


Where:

$\mathrm{P}_{\text {nti }}$ stands for an organization's profit after implementing neurotechnologies in its research, production, trade and management activities;

A stands for the money terms of the cost of the organization's assets;

ROA stands for the rentability of the organization's assets;

$\mathrm{K}_{\mathrm{ri}}, \mathrm{K}_{\mathrm{pi}}, \mathrm{K}_{\mathrm{ti}}, \mathrm{K}_{\mathrm{mi}}$; stand for the ratios which have the values equalling more than 1 and expressing the increase of the assets 'rentability (the efficiency increase of the organization's activity) in the result of implementing neurotechnologies, correspondingly, in the research, production, trade and management spheres of the organization's activity.

\section{DisCUSSION}

The analysis of the sources which is performed in this research shows that researchers suppose the sphere of neurotechnological mechanical engineering to be quite promising and opening great opportunities for the future development of this engineering sector.

However, experts still do not include the development of neurotechnologies in the process and structure of forming the sixth technological order. The present comparative analysis of the problems solved within the sixth technological order and of the problems that can be solved by means of neurotechnologies has shown that such problems are close. This allows to suggest that the development of neurotechnologies (alongside with nanotechnologies) is an important structural element in the process of forming the sixth technological order. The further development and application of neurotechnologies in all the stages of services and commodities 'life cycle (production, turnover, consumption) and spreading of these technologies over more spheres of socio-economic activity can help to increase the market demand for the development of methods, technologies, design and production of hardware complexes for neurotechnological activity. The increase of the demand for neurotechnological equipment will be the basis for forming neuromarketing engineering as a sub-discipline of mechanical engineering and a sub-sector of economics within the sixth technological order.

The actual uses of neuromarketing methods and tools for transporting goods by means of vehicles have been considered in the research [22, p. 201-212]. The development of neuroengineering within the legislation function of the general theory of neurotechnologies will require the development of its legal coverage (legislative framework) with respect to social, ethnic limitations and to the observance of human rights, as it is represented in the works $[18$, p.249-250; 22, p.p. 201-212; 23, p.182192].

The expansion of using game approach (gamification) can become an important structural segment of neurotechnology development within the sixth technological order in the spheres of educational technologies and professional education, including staff drills for rational reacting in emergencies and crises. Such education using neurotechnologies can be headed for increasing staff's psychological stability in non-standard situations and can be considered as a way of reducing and limiting organizations 'losses in stressful situations and hazards.

The application of neurotechnologies for increasing management efficiency in organizations by using resources within the accomplishment of the management functions (planning, organization, motivation, supervision) has been considered in the article [23, p. 182192]. It should be noted that the usage of neurotechnologies in designing new products (goods and commodities) is referred to trade neuromarketing in the beginning of the 21 st century but due to the fact that innovations and research, research and development (R\&D) works act as an independent sphere of engineering design bureau's activity, research neurotechnologies can be identified as an independent segment of neurotechnology development in engineering of the sixth technological order. Nowadays, it is possible to identify the following practical aspects of neurotechnologies' development: research, production, trade and management vectors of neurotech development. Herewith, several management neurotechnologies can already be identified in the fields of planning, organization, motivation and activity supervision in organizations. As it is reasonable to predict the spreading and development of neurotechnologies in more spheres of human activity, it is practically useful to form methods for analyzing the possibilities of using neurotechnologies in any field.

The methods for examining the possibilities of using neurotechnologies in a certain sphere of activity may consist of the following stages:

1) Technologies of a certain type of activity are described in planning sheets as sequences (flow charts) of logically interconnected procedures (operations);

2) Each procedure included in a planning sheet is examined for the presence of technical setting (fixing) conditions and the ones of taking the readings of nerve and/or biochemical reactions running during the completion of this procedure in the organism of an employee or a customer;

3) In case if the possibilities of technical registration and of taking the readings are present, it means that this technology has a potential of its neurotechnological implementation;

4) In case if the possibilities for technical registration and for taking the readings of staff's biochemical reactions are absent, the decision is 
made about the inability to use neurotechnologies in this sphere of activity;

5) All procedures included in the planning sheets of the work in the organization are examined for the probability of employee's inexpedient, inefficient and unpredictable movements and actions;

6) If there is a possibility of employees 'inexpedient actions, a conclusion can be made about the need (motive) for implementing neurotechnologies in this procedure of the technological process within the organization's activity;

7) If there is not a possibility of employees ' inexpedient actions, a conclusion can be made about the impossibility of implementing neurotechnologies in this procedure of the technological process within the organization's activity;

8) All technological procedures stated in the planning sheet are examined for the possibility and/or probability of employees 'corrupted or unfair performance of their duties, and for the presence of employees 'possibility of manipulating other employees in the process of their cooperation in the organization;

9) If such probability is discovered, it is recommended to acknowledge the presence of a reason (motive) for examining the implementation of neurotechnologies in this type of procedures within the technological process;

10) If the conclusion is drawn about the absence of the probability of corrupted, unfair or manipulative actions taken by any category of workers, the implementation of neurotechnologies is declared inexpedient;

11) For all the procedures stated in the planning sheet of the organization's activity, the possibility of increasing their efficiency is examined in terms of performing them by implementing game approach (gamification) in the process of training the workers to perform this procedure;

12) If such possibility is discovered, it should be recommended to implement neurotechnologies in this sphere of the organization's work;

13) If the possibility of the gamification of the procedure performance training process is absent, the implementation of neurotechnologies in this aspect and in this sphere of organization's activity is declared impossible;

14) Analysis is conducted to determine the significance of the discovered possibilities and the needs (motives) for implementing neurotechnologies, with respect to the predictive economic efficiency of implementing neurotechnologies in the technological process of the organization's activity;
15) If the implementation of neurotechnologies in the technological process of the organization's activity is considered to be effective, the development of the implementation project is conducted;

16) The project of the implementation of neurotechnologies in the technologies of the organization's activity is practically carried out;

17) Observation is conducted, so is the assessment of a posteriori economic efficiency of the project of implementing neurotechnologies in the organization's technological processes.

In the process of completing the algorithm of examining both the possibility of implementing neurotechnologies and the economic efficiency of implementing neurotechnologies, allowance must be made for the specific characteristics of the considered technological activity of an organization and for their impact on employees 'behavior and psychology in a certain sphere of activity.

It should be taken into account that the further development of neurotechnologies will cause demand and thus, a market niche for the development of neurotechnology engineering (neuroengineering) within the sixth technological order.

In favor of rapid and successful mastering the opportunities of this market and also production niche by domestic engineering, it can be recommended to establish a public organization (association) for neurotechnological research, to set up a neurotechnological platform and/or a cluster within domestic engineering and to create neurotechnology engineering departments at specialized universities, etc.

Probably, the conversion of scientific knowledge in this field may help to accelerate the establishment of the neurotechnological platform within the post industrial engineering of the sixth technological order.

Another important element of the neuroengineering formation process can be the development of a scientific discussion on this topic together with the comprehensive and considered discussion of prospectives, order of stages and limitations (restrictions) on developing neuroengineering by the scientific and professional communities.

Herewith, neurotechnological scientific platform can be identified as a collection of knowledge from different fields that is necessary for the successful development of neuroengineering within the sixth technological order [30].

\section{Conclusion}

The research of scientific results in the field of neurotechnologies has been carried out in this article, which allows to suggest that the probable reasons for the 
acceleration of neurotechnological development are the cost increase of wrong solutions in business processes on the one hand, and on the other hand, the opportunities provided by the nanotechnological development of intellectual and information technologies; the opinion is established that neurotechnologies are to be considered as a structural element of the sixth technological order development; the forecast is performed concerning the expansion of the neuroengineering market niche; the methodology of neurotechnologies is added, the functions and roles of the theory of neurotechnologies are described; the increase of the number of practical aspects of using neurotechnologies is established; criteria and mathematical formulae (models) for assessing the processes of development and economic efficiency of the implementation of neurotechnologies in organizations ' activity are provided; the algorithm for planning (projecting) the neurotechnological development of organizations is suggested; the expediency of setting up a public organization for neuroengineering research is established; the possibility of forming a neurotechnological platform and clusters is explained; the active use of methods of conversing scientific knowledge in domestic engineering within the formation of neuroengineering as a part of the sixth technological order is established.

\section{REFERENCES}

[1] Glushchenko V. V. The paradigm of intellectual management of the formation of the sixth technological order in the economy// The scientific heritage, 2020, vol. 4, No. 45 (2020), p.54-63.

[2] Glazyev, S.Y. Global Economic Paradigms in Global Economic Development/Economics and Mathematical Methods. 2016. Volume 52. № 2. P. 3-29

[3] Egorov, N.E., Kovrov, G.S., Nikiforova, V.V. The Main Aspects of Technological Development of the Republic of Sakha (Yakutia) During the Transition to The Sixth Technological Order // In the collection: Innovative Clusters in Digital Economy: Theory and Practice. The Works of the 8th Practical Research Conference with International Participants. Edited by A.V. Babkin. 2017. P. 247-251.

[4] Petrushenko A. S. Neurotechnologies in urban transport traffic management//Exact science. 2019. No. 51. pp. 2-3.

[5] Dorzhieva, S.C. Neuroeconomics and Neuromarketing as Tools of a Modern Enterprise // Russian Economic Internet Journal. 2018.No. 3. P. 30

[6] Sazonov, A.E. Neurotechnologies: the Present and the Future // Scientific and Technical Collection of the Russian Marine Register of Shipping. 2009. No. 32. P. 220-234.

[7] Chabanov, V.A. The Use of Neurotechnologies in Reducing Pilot Workloads // Aviation Systems. 2015. No. 3. P. 43-47.

[8] Abu-Abed, F.N., Borisov, N.A., Khabarov, A.R. The Use of Neurotechnologies for the Analysis of Situations in Managing Complex Objects // In the collection: Mathematical Methods and Information Technologies in Economics, Sociology and Education: 16th International Research Conference: Collection of Works. Edited by V.I. Levin. 2005. P. 409-412.

[9] Zhukova (Borachuk), O.V., Shelepin, Y.E., Maksimova, V.A., Ekimov, P.A., Pronin, S.V. Neurotechnologies and Decision Making Under Uncertainty // In the collection: Technological Perspective Within the Eurasian Space: New
Markets and Points of Economic Growth 1st International Scientific Conference: conference proceedings. 2015. P. 173176.

[10] Korolkov, A.P., Kolesnikov, D.A., Khakhanov, E.A., Prospects for the Use of Neurotechnologies for Monitoring the State of Oil Trunk Pipelines in the Arctic Zone // Problems of Risk Management in the Technosphere. 2016. No. 3 (39). P. 6-12.

[11] Ovchinnikova, V.A., Fomin, V.A., Ivashov, S.V. Prospects for the Use of Neurotechnologies in Production Processes in Enterprises of the New Industry // In the collection: Works of Conferences of the State Research Institute of National Development. December 2016 Collection of Selected Articles. Editor-in-chief Y.F. Elsesser. Responsible for the Release L.A. Pavlov. 2016. P. 82-85.

[12] Poskotinova, L.V., Demin, D.B., Transformation of Biological and Social Feedbacks in the Development of Neurotechnologies // Biomedical Radioelectronics. 2016. No. 5. P. 21-23.

[13] Buzskaya, O.M. The Potential of Neurotechnologies in the Formation of New Guidelines for Socio-cultural Space // Law and Practice. 2016. No. 4. P. 183-187.

[14] Panasenko, S.V., Kazantseva, S.Y. The Role and Significance of Neurotechnologies in the Digital Economy // In the collection: Digital Economy and Education Moscow, 2018. P. 35-38.

[15] Korolev, A.A. Neurotechnologies as a Factor in the Formation of New Industries and the Economy of Russia // In the collection: Foresight "Russia": New Production for the New Economy Collection of Materials of the St. Petersburg International Economic Congress (SPEC-2016). 2016. P. 393-400.

[16] Panasenko, S.V., Mkrtchyan, V.S. Prospects for the Use of Neurotechnologies in Various Sectors of the Digital Economy // Russian Journal of Entrepreneurship. 2018. Vol. 19. No. 11. P. 3269-3278.

[17] Bushmanova, N.V. The Introduction of Neurotechnologies in Education // In the Collection: The Goals and Values of Modern Education Materials of the Russian National Practical Research Conference with International Participants. Editor-in-chief V.E. Blueberry. 2019. P. 205207.

[18] Elyashevich, A.M. Neurotechnology, Fantastic Prospects and Real Dangers // In the Collection: Technological Perspective within the Eurasian Space: New Markets and Points of Economic Growth, Works of the 2nd International Conference. 2016. P. 249-250.

[19] Larina, Y.M. The Place of the Russian Federation in the Global Market of Neurotechnologies // Economics and Management: Problems, Solutions. 2019. Vol. 3. No. 3. P. 14-18.

[20] Molchanov, N.N., Muravyova, O.S., Galai, N.I. Neurotechnologies: the Assessment of Development Prospects in Russia // Udmurt University Bulletin. Economics and Law Series. 2019. Vol. 29. No. 2. P. 142-151.

[21] Roadmap for the Development of End-to-End Digital Technology "Neurotechnology and Artificial Intelligence" // Research Report / Ministry of Digital Development, Communications and Mass Media of the Russian Federation, https://digital.gov.ru/uploaded/files/07102019ii.pdf (accessed 10.10.2019)

[22] Glushchenko, V.V., Glushchenko, I.I., Plakhotin, E.O., Shinaeva, A.I. Management of Neuromarketing in the Service Sector on Railway Transport [Electronic Resource] // Youth Research Journal. 2017. No. 11 (24), P. 201-212. URL: (http://www.mnvnauka.ru/2017/11/Glushchenko.pdf (Released 11.17.2017). 
[23] Glushchenko, V.V., Glushchenko, I.I. The Development of Methodology and Practical Directions of Managerial Neuromarketing // Science and Practice Journal. 2018. Vol. 4. No. 3. P. 182-192.

[24] Glushchenko, V.V., Glushchenko, I.I. Science as a Methodological Basis for Increasing the Efficiency of the National Innovation System // the Internet Journal Science. 2015. Vol. 7. No. 1 (26). P. 5., DOI: 10.15862 / 65EVN115.

[25] Kotler, F. Fundamentals of Marketing: Translation from English - M.: "Business Book", "IMA-Cross. Plus ", 1995. 702 pages.

[26] Langlois, R. N., Cosgel, M. M. Frank Knight on Risk, Uncertainty, and the Firm: a New Interpretation // Economic Inquiry. V. XXXI, July 1993. P. 456 - 465.

[27] Glushchenko, V. V, Glushchenko, I. I. Corporate Risks of Innovative Entrepreneurship in the Context of the Global Crisis. M .: Economics and Entrepreneurship. 2014. No. 10. P. 848 - 856.

[28] Glushchenko, V.V., Glushchenko, I.I. The Analysis of Risk Factors Affecting the Financial Result of an Innovative Project in High-Tech Mechanical Engineering // Problems of Mechanical Engineering and Automation. 2014. No. 4, P. 3746.

[29] Knyshova, E.N. Marketing. Study guide. - M .: Publishing House "FORUM": INFRA-M. 2009. P. 13.

[30] Glushchenko, V.V. Machineology as a Conceptual Basis for the Formation of a Mining Engineering Research Platform // International Conference on Innovations and Prospects of Development of Mining Machinery and Electrical Engineering 2019, 24-27 April 2019, Saint-Petersburg Mining University, Saint- Petersburg, Russian Federation: https://iopscience.iop.org/issue/1755-1315/378/1 